femoral artery with a razor. In 1864 the American Dental Association, and in 1870 the American Medical Association, declared Wells to be the real discoverer of anæsthesia.

\section{Animal and Human Sex Behaviour}

ANImaL and human sex behaviour are the subjects of five papers published in the Annals of the New York Academy of Sciences (47, Art. 5, 603-664; May 1947). These papers were given at a conference on physiological and psychological factors in sex behaviour held by the Sections of Biology and Psychology of the Academy in March 1946. Prof. S. B. Wortis, in his introduction, says that the conference revealed new material and indicated correlations which emphasize the need to change our attitudes to human sexual behaviour, and he hopes that this material may help to modify the law relating to these matters. $\mathrm{He}$ was speaking to Americans, but progressive opinion in Britain has more than once expressed a similar point of view. American and British cultures are not so different that they cannot, in matters like this, be regarded as one. Many of the opinions expressed at this conference will therefore interest British readers of them. There are two papers on animal sex behaviour by W. C. Young, who discusses animal endocrines, and W. E. Galt, whose subject is primate sex behaviour. A. C. Kinsey spoke briefly upon sex behaviour in the human animal, Morris Herman gave a paper on aberrant sex behaviour, and Gregory Bateson gave one on sex and culture.

\section{Historical and Philosophical Society of Jerusalem}

In has often been said that the academic discipline provides a foundation on which international collaboration can be built. The Jerusalem Historical and Philosophical Society, formed in March 1946, with the object of promoting the study of history, philosophy and literature among the Arab, British and Jewish communities of Palestine, is good evidence of such collaboration. The Society meets once a month, when papers are read by members or guest lecturers, and the three subjects, history, philosophy and literature are taken in rotation, four papers a year being devoted to each subject. Membership is limited and is by invitation only, the sole qualification being an academic interest in one of the three subjects. At present, several of the Arab members belong to the Government Arab College, British members are drawn from the staff of the British Council in Palestine, and Jewish members from the staff of the Hebrew University; the Department of Education is also represented. So far it has not been possible to print papers in full; but Dr. W. Yourgrau has produced short summaries of seven papers presented during the Society's first year. The president is Sir William FitzGerald, chief justice of Palestine, and the honorary secretary and treasurer is Miss $\mathbf{E}$. Cunnington, Jerusalem, P.O. Box 2.

\section{Calcutta Statistical Association Bulletin}

THE publication of Sankhyā, one of the leading statistical journals, and the work of Prof. P. C. Mahalanobis, Dr. P. V. Sukhatme and others for national and international statistics, establish India's claim to be considered in the front rank of nations contributing to the theory and application of statistical science. The Calcutta Statistical Association, a new society, has produced a Bulletin, the modest aim of which is to publish popular ex- positions of statistics ; if the journal has the support of the Calcutta school, a high standard should be assured. The first number (No. 1. August 1947. Pp. 1-48. Calcutta, 3s.) contains an interesting brief history of crop-sampling in India from the time of Akbar to the present day, a criticism of the recent report of the Indian Central Pay Commission, simple accounts of statistical aspects of public opinion surveying and mental testing, and several shorter notes. The problem of making modern statistical techniques intelligible to readers who lack formal training in the subject has been courageously, though not always successfully, tackled. A more critical approach and increased care in the choice of words should make this Bulletin of considerable interest and value outside, as well as inside, India.

\section{Modern Apparatus for Visual Aids}

A RECENT publication offers a priced catalogue of representative items in the range of equipment for visual aids in education (Visual Aids : Notes on some Modern Apparatus. By Wilfred J. Garnett. Pp. 36. Manchester : Flatters and Garnett, Ltd., 1947). Each instrument is concisely described, and the pros and cons of each corresponding method of visual presentation are outlined with admirable fairness and objectivity. The most spectacular of the items listed are probably the microprojector and the patent demonstration mirror; the former as an example of functional efficiency, the latter in view of its comparatively recent development as a visual aid. As a guide to the purchaser of equipment who seeks the best possible results in the way of visual reproduction the author is thoroughly dependable. (The section on "Types of Screen" is particularly helpful, and the actual specimen of 'beaded' screen material does all that is claimed for it.) Technical perfection, however, is not always the last criterion. The technical limitations of film strip sometimes make slides preferable. Yet the growing popularity of film strip among teachers cannot be questioned. The advantages of lightness, compactness and, above all, cheapness are overwhelming. Film strip has come to stay; can science now produce the non-scratch film ?

\section{Danish Institution of Civil Engineers}

IN response to an invitation received from the Danish Institution of Civil Engineers (Dansk Ingeniørforening) Sir Stanley Angwin is representing the presidents of the Institution of Civil Engineers, the Institution of Mechanical Engineers and the Institution of Electrical Engineers in Copenhagen on January 21 and 22 in the celebrations organised by the Danish Institution to mark the opening of their rebuilt headquarters building "Engineering House". The new headquarters replace the Institution's building totally destroyed by the R.A.F. in the spring of 1945 , together with the next-door building which the Germans were using as Gestapo headquarters.

\section{International Union of Crystallography}

AT the invitation of the American Society for $\mathrm{X}$-ray and Electron Diffraction and of the Crystallographic Society of America, the first General Assembly and International Congress of the Union will be held at Harvard University, Cambridge, Mass., U.S.A., during July 28-August 3, 1948. Delegates to the General Assembly will be nominated by the national academies of countries adhering to the Union; but all erystallographers are cordially 